\title{
Exploratory field study on the effects of porcine circovirus 2 (PCV-2) sow vaccination at different physiological stages mimicking blanket vaccination
}

Patricia Pleguezuelos ${ }^{1,2^{*}}$ D, Marina Sibila ${ }^{1,2}$, Raúl Cuadrado ${ }^{1,2}$, Rosa López-Jiménez ${ }^{1,2}$, Diego Pérez ${ }^{1,2}$, Eva Huerta ${ }^{1,2}$, Anna M. Llorens ${ }^{1,2}$, José Ignacio Núñez ${ }^{1,2}$, Joaquim Segalés ${ }^{2,3,4}$ and Sergio López-Soria ${ }^{1,2}$

\begin{abstract}
Background: The objective of the present study was to explore the benefits of Porcine circovirus 2 (PCV-2) blanket vaccination in a sow herd on productive parameters, PCV-2 infection and immune status in sows and their progeny. For this purpose, 288 sows were distributed among four balanced experimental groups. One group remained as negative control group and the other three received $1 \mathrm{~mL}$ of PCV-2 Ingelvac Circoflex ${ }^{\oplus}$ intramuscularly at different productive cycle moments: before mating, mid gestation (42-49 days post-insemination) or late gestation (86-93 days post-insemination); phosphate buffered saline (PBS) was used as negative control item. Reproductive parameters from sows during gestation and body weight of their progeny from birth to weaning were recorded. Additionally, blood was collected from sows at each vaccination time and piglets at 3 weeks of age. Moreover, up to 4 placental umbilical cords (PUC) per sow were taken at peri-partum. Sera from sows and piglets were analysed for PCV-2 antibody detection using an enzyme-linked immunosorbent assay (ELISA). Sera from sows and PUC were tested to quantify viraemia using a real time quantitative polymerase chain reaction (qPCR) assay.
\end{abstract}

Results: Globally, results indicated that vaccinated sows showed heavier piglets at birth and at weaning, less crossfostered piglets, lower viral load at farrowing as well as in PUC, and higher antibody levels at farrowing, compared to non-vaccinated ones. When all groups were compared among them, sows vaccinated at mid or late gestation had heavier piglets at birth than non-vaccinated sows, and lower proportion of PCV-2 positive PUC. Also, crossfostering was less frequently practiced in sows vaccinated at pre-mating or mid gestation compared to nonvaccinated ones.

Conclusions: In conclusion, the present study points out that PCV-2 sow vaccination at different time points of their physiological status (mimicking blanket vaccination) offers benefits at production and serological and virological levels.

Keywords: Porcine circovirus type 2, Blanket vaccination, Sow, Piglet, Production parameters

\footnotetext{
* Correspondence: patricia.pleguezuelos@irta.cat

${ }^{1}$ IRTA, Centre de Recerca en Sanitat Animal (CReSA, IRTA-UAB), Campus de la Universitat Autònoma de Barcelona, 08193 Bellaterra, Spain

${ }^{2}$ OIE Collaborating Centre for the Research and Control of Emerging and

Re-emerging Swine Diseases in Europe (IRTA-CReSA), Bellaterra, Spain

Full list of author information is available at the end of the article
}

C C The Author(s). 2021 Open Access This article is licensed under a Creative Commons Attribution 4.0 International License, which permits use, sharing, adaptation, distribution and reproduction in any medium or format, as long as you give appropriate credit to the original author(s) and the source, provide a link to the Creative Commons licence, and indicate if changes were made. The images or other third party material in this article are included in the article's Creative Commons licence, unless indicated otherwise in a credit line to the material. If material is not included in the article's Creative Commons licence and your intended use is not permitted by statutory regulation or exceeds the permitted use, you will need to obtain permission directly from the copyright holder. To view a copy of this licence, visit http://creativecommons.org/licenses/by/4.0/. The Creative Commons Public Domain Dedication waiver (http://creativecommons.org/publicdomain/zero/1.0/) applies to the data made available in this article, unless otherwise stated in a credit line to the data. 


\section{Background}

Porcine circovirus 2 (PCV-2) is a small, circular, nonenveloped, single-stranded DNA virus of $20 \mathrm{~nm}$ in diameter approximately, belonging to the genus Circovirus, family Circoviridae [1]. This virus is ubiquitous in the pig population [2-6] and is the etiologic agent of clinical diseases and subclinical infection comprised under the term of porcine circovirus diseases [7].

Intrauterine PCV-2 infections in different stages of pregnancy may cause different reproductive disorders depending on the foetal immunological competence [8], the so-called PCV-2 reproductive disease. Intrauterine PCV-2 infection of foetuses, via insemination or transplacental, may cause late-term abortions, mummified, stillborn and weak born piglets [9-14]. Furthermore, pigs may be born PCV-2 viraemic due to transplacental infection that may subsequently act as an infection focus for their pen mates. All these situations imply that infected sows have a very important role in PCV-2 infection maintenance and dissemination in the herd due to horizontal and vertical infection transmission.

Nowadays, vaccination is a very effective tool to control PCV-2 infection. From 2007 to present, four major PCV-2 vaccines have been marketed worldwide [15], but only two are licensed in several countries for their use in sows to protect their progeny. Therefore, current products allow applying different vaccination regimes combining piglet and/or sow vaccination [16, 17]. These abovementioned vaccines are an inactivated PCV-2a vaccine, a recombinant vaccine based on an inactivated PCV-1/PCV-2a chimeric virus or subunit vaccines based on a PCV-2a Cap protein. Specifically, the vaccine tested in this study, Ingelvac Circoflex ${ }^{\odot}$, is a PCV-2a subunit vaccine based on the product of the ORF2 gene expressed in a baculovirus system [15]. However, crossprotection between the major genotypes worldwide (PCV-2a, PCV-2b and PCV-2d) has been observed in experimental trials and field studies [18-20].

Different studies have shown the capacity of the sow vaccination to induce an immune response and the transfer of passive immunity to the offspring. Sow vaccination before mating stabilizes and homogenizes the PCV-2 immune status of the sow population during gestation [2124]. Sow vaccination administered before farrowing can confer protection through maternally derived immunity to their offspring against PCV-2 systemic disease by reducing viraemia [16], lesions and viral load in tissues [25] as well as increasing their average daily weight gain in PCV-2 subclinical infection [22]. When this vaccination strategy is boosted in the following reproductive cycles at 3 weeks before farrowing (for 3 years), an improvement of the reproduction rate, number of piglets born alive, birth weight of piglets and number of piglets weaned per a litter was achieved [26]. Another study, where the boost was applied on the second cycle at 2 weeks before farrowing, reported higher number of live-born piglets per litter at the second cycle and higher vitality score from the fist cycle [13] compared to the non-vaccinated (NV) group. Nevertheless, the effect of PCV-2 sow vaccination strategies on reproductive parameters has been, up to now, scarcely studied $[13,26]$. Furthermore, practices in the field have explored the option of sow blanket vaccination (personal communication of field veterinarians); however, no contrasted data has been scientifically described.

Hence, the objective of the present work was to evaluate the effects of sow vaccination against PCV-2 applied at different stages of the production cycle (before mating, mid gestation and late gestation), mimicking a blanket vaccination fashion, on productive parameters as well as on virological and serological parameters in sows and their progeny.

\section{Results}

\section{Productive parameters}

Productive parameters from gilts/sows and piglets from the three vaccinated $(\mathrm{V})$ groups taken together and the non-vaccinated (NV) group are shown in Table 1 . The comparison of these parameters among each treatment group are detailed in Table 2 . In both tables, statistically significant differences and tendencies are indicated.

\section{PCV-2 antibody values in serum samples of sows and piglets}

PCV-2 IgG and IgM ELISA optical density (OD) values of sows

Sow blood samples collected at the three vaccine/PBS application times as well as at farrowing were used to determine the dynamics of IgG antibodies against PCV2 (Fig. 1). Each of the different $\mathrm{V}$ treatments showed significantly higher IgG values than the NV group from the sampling after their vaccine application until farrowing. At this point, no statistically significant differences between sows vaccinated at mid (V MG) and late (V LG) nor between sows vaccinated at pre-mating (V PM) and V MG group were observed.

In general terms, the PCV-2 IgM OD values of the four groups were very low (mean OD values between $0.40 \pm 0.14$ and $0.51 \pm 0.20$ at the different sampling points, data not shown) and no statistical differences in OD values between each experimental group at any time point were found.

\section{PCV-2 IgG ELISA S/P values of weaned pigs}

Blood samples from 4 to 6 randomly selected piglets per each sow were taken at weaning and used to detect PCV-2 antibodies. Mean PCV-2 S/P values per treatment groups are represented in Fig. 2. Piglets from $\mathrm{V}$ sows showed significantly higher $\mathrm{PCV}-2 \mathrm{~S} / \mathrm{P}$ values than 
Table 1 Productive parameters (mean \pm SD or proportion [percentage] plus confidence interval [CI]) of $\vee$ and NV sows

\begin{tabular}{|c|c|c|}
\hline & V & NV \\
\hline Total born piglets /sow & $14.1 \pm 3.0^{\mathrm{a}}$ & $13.6 \pm 3.6^{\mathrm{a}}$ \\
\hline Live born piglets/sow & $13.4 \pm 3.0^{\mathrm{a}}$ & $12.9 \pm 3.7^{\mathrm{a}}$ \\
\hline Weaning-to-mate interval (days) & $4.6 \pm 5.1^{\mathrm{a}}$ & $4.6 \pm 5.0^{\mathrm{a}}$ \\
\hline Weaning-to-fecundation interval (days) & $30.7 \pm 7.0^{\mathrm{a}}$ & $30.2 \pm 5.3^{\mathrm{a}}$ \\
\hline Weaned piglets/sow & $12.1 \pm 2.7^{\mathrm{a}}$ & $11.8 \pm 3.7^{\mathrm{a}}$ \\
\hline Abortions & $\begin{array}{l}4 / 180(2.2 \%)^{a} \\
\text { Cl: } 0.1-4.4 \%\end{array}$ & $\begin{array}{l}2 / 53(3.8 \%)^{\mathrm{a}} \\
\mathrm{Cl}:-1.4-8,9 \%\end{array}$ \\
\hline Mummies & $\begin{array}{l}34 / 2424(1.4 \%)^{a} \\
\text { Cl: } 0.9-1,9 \%\end{array}$ & $\begin{array}{l}15 / 695(2.2 \%)^{\mathrm{a}} \\
\text { Cl: } 1.1-3.2 \%\end{array}$ \\
\hline Stillbirth & $\begin{array}{l}105 / 2424(4.3 \%)^{a} \\
\text { Cl: } 3.5-5.1 \%\end{array}$ & $\begin{array}{l}24 / 695(3.5 \%)^{\mathrm{a}} \\
\text { Cl: } 2.1-4.8 \%\end{array}$ \\
\hline Dead suckling piglets & $\begin{array}{l}213 / 2295(9.3 \%)^{a} \\
\text { Cl: } 8.1-10.5 \%\end{array}$ & $\begin{array}{l}58 / 658(8.8 \%)^{\mathrm{a}} \\
\text { Cl: } 6.6-11.0 \%\end{array}$ \\
\hline Cross-fostered piglets & $\begin{array}{l}127 / 2079(6.1 \%)^{a} \\
\text { Cl: } 5.1-7.1 \%\end{array}$ & $\begin{array}{l}53 / 600(8.8 \%)^{b} \\
\text { Cl: } 6.6-11.1 \%\end{array}$ \\
\hline Piglets birth weight (Kg) & $1.64 \pm 0.39^{\mathrm{a}}$ & $1.58 \pm 0.38^{b}$ \\
\hline Weaned piglet weight (Kg) & $6.51 \pm 1.48^{\mathrm{a}}$ & $6.37 \pm 1.48^{b}$ \\
\hline
\end{tabular}

Different letters in superscript in a row indicate significant differences $(p \leq 0.05)$ between $V$ and NV groups (highlighted in bold)

$\checkmark$ Vaccinated, NV Non-vaccinated

piglets from NV sows. The highest values were obtained in piglets from V MG and V LG sows.

\section{qPCR to detect PCV-2}

\section{$P C V-2$ DNA in sow serum samples}

Blood samples from sows taken at the three vaccine/PBS application times as well as at farrowing were used to assess the proportion of PCV-2 qPCR positive sera from $\mathrm{V}$ and NV animals (Table 3 ).

Only three sows were positive to qPCR through the study: One V animal from V PM group was positive at mid gestation sampling point $\left(10^{4.2} \mathrm{PCV}-2\right.$ copies $\left./ \mathrm{mL}\right)$, and two NV sows were positive at farrowing (one with $10^{5.3} \mathrm{PCV} 2$ copies $/ \mathrm{mL}$ and another one below the limit of quantification (LOQ $=10^{4.00} \mathrm{PCV}-2$ genome copies/

Table 2 Productive parameters (mean \pm SD or proportion [percentage] plus Cl) of the four studied experimental groups

\begin{tabular}{|c|c|c|c|c|}
\hline & V PM & V MG & V LG & NV \\
\hline Total born piglets /sow & $14.1 \pm 2.8^{\mathrm{a}}$ & $13.9 \pm 2.5^{\mathrm{a}}$ & $14.3 \pm 3.5^{a}$ & $13.6 \pm 3.6^{a}$ \\
\hline Live born piglets/sow & $13.3 \pm 2.7^{\mathrm{a}}$ & $13.5 \pm 2.6^{\mathrm{a}}$ & $13.4 \pm 3.6^{a}$ & $12.9 \pm 3.7^{a}$ \\
\hline Weaning-to-mate interval (days) & $4.2 \pm 3.6^{a}$ & $4.7 \pm 5.9^{a}$ & $4.8 \pm 5.7^{a}$ & $4.6 \pm 5.0^{a}$ \\
\hline Weaning-to-fecundation interval (days) & $30.7 \pm 7.7^{a}$ & $30.6 \pm 6.7^{a}$ & $30.7 \pm 6.6^{a}$ & $30.2 \pm 5.3^{a}$ \\
\hline Weaned piglets/sow & $12.0 \pm 2.5^{\mathrm{a}}$ & $12.2 \pm 2.4^{\mathrm{a}}$ & $12.1 \pm 3.1^{\mathrm{a}}$ & $11.8 \pm 3.7^{\mathrm{a}}$ \\
\hline Abortions & $\begin{array}{l}1 / 60(1.7 \%)^{a} \\
C l:-1.6-4.9 \%\end{array}$ & $\begin{array}{l}3 / 59(5.1 \%)^{a} \\
\text { Cl: }-0.5-10.7 \%\end{array}$ & $\begin{array}{l}0 / 61(0.0 \%)^{a} \\
C l: 0.0 \%\end{array}$ & $\begin{array}{l}2 / 53(3.8 \%)^{a} \\
C l:-1.4-8,9 \%\end{array}$ \\
\hline Mummies & $\begin{array}{l}9 / 815(1.1 \%)^{A} \\
\text { Cl: } 0.4-1.8 \%\end{array}$ & $\begin{array}{l}10 / 753(1.3 \%)^{A, B} \\
C l: 0.5-2.1 \%\end{array}$ & $\begin{array}{l}15 / 856(1.8 \%)^{A, B} \\
C l: 0.9-2.6 \%\end{array}$ & $\begin{array}{l}15 / 695(2.2 \%)^{B} \\
C I: 1.1-3.2 \%\end{array}$ \\
\hline Stillbirth & $\begin{array}{l}37 / 815(4.5 \%)^{a} \\
\text { Cl: } 3.1-6.0 \%\end{array}$ & $\begin{array}{l}27 / 753(3.6 \%)^{a} \\
\text { Cl: } 2.3-4.9 \%\end{array}$ & $\begin{array}{l}41 / 856(4.8 \%)^{a} \\
\text { Cl: } 3.4-6.2 \%\end{array}$ & $\begin{array}{l}24 / 695(3.5 \%)^{a} \\
\text { Cl: } 2.1-4.8 \%\end{array}$ \\
\hline Dead suckling piglets & $\begin{array}{l}74 / 769(9.6 \%)^{a} \\
C l: 7.5-11.7 \%\end{array}$ & $\begin{array}{l}67 / 727(9.2 \%)^{a} \\
C l: 7.1-11.3 \%\end{array}$ & $\begin{array}{l}72 / 799(9.0 \%)^{a} \\
C l: 7.0-11.0 \%\end{array}$ & $\begin{array}{l}58 / 658(8.8 \%)^{a} \\
C l: 6.6-11.0 \%\end{array}$ \\
\hline Cross-fostered piglets & $\begin{array}{l}40 / 694(5.8 \%)^{a, A, B} \\
\text { Cl: } 4.0-7.5 \%\end{array}$ & $\begin{array}{l}33 / 659(5.0 \%)^{\mathrm{a}, \mathrm{A}} \\
\text { Cl: } 3.3-6.7 \%\end{array}$ & $\begin{array}{l}54 / 726(7.4 \%)^{a, b, B} \\
\text { Cl: } 5.5-9.3 \%\end{array}$ & $\begin{array}{l}53 / 600(8.8 \%)^{b, A, B} \\
C l: 6.6-11.1 \%\end{array}$ \\
\hline Piglets birth weight (Kg) & $1.62 \pm 0.40^{\mathrm{a}, \mathrm{b}}$ & $1.66 \pm 0.38^{a}$ & $1.64 \pm 0.39^{a}$ & $1.58 \pm 0.38^{b}$ \\
\hline Weaned piglet weight (Kg) & $6.49 \pm 1.50^{a}$ & $6.52 \pm 1.48^{a}$ & $6.52 \pm 1.45^{a}$ & $6.37 \pm 1.48^{a}$ \\
\hline
\end{tabular}

Different letters in superscript in a row indicate significant differences ( $p \leq 0.05$ for lower case letters) or tendency ( $p \leq 0.10$ for capital letters) among experimental groups (highlighted in bold)

V PM Vaccinated pre-mating, V MG Vaccinated at mid gestation, V LG Vaccinated at late gestation, NV Non-vaccinated 


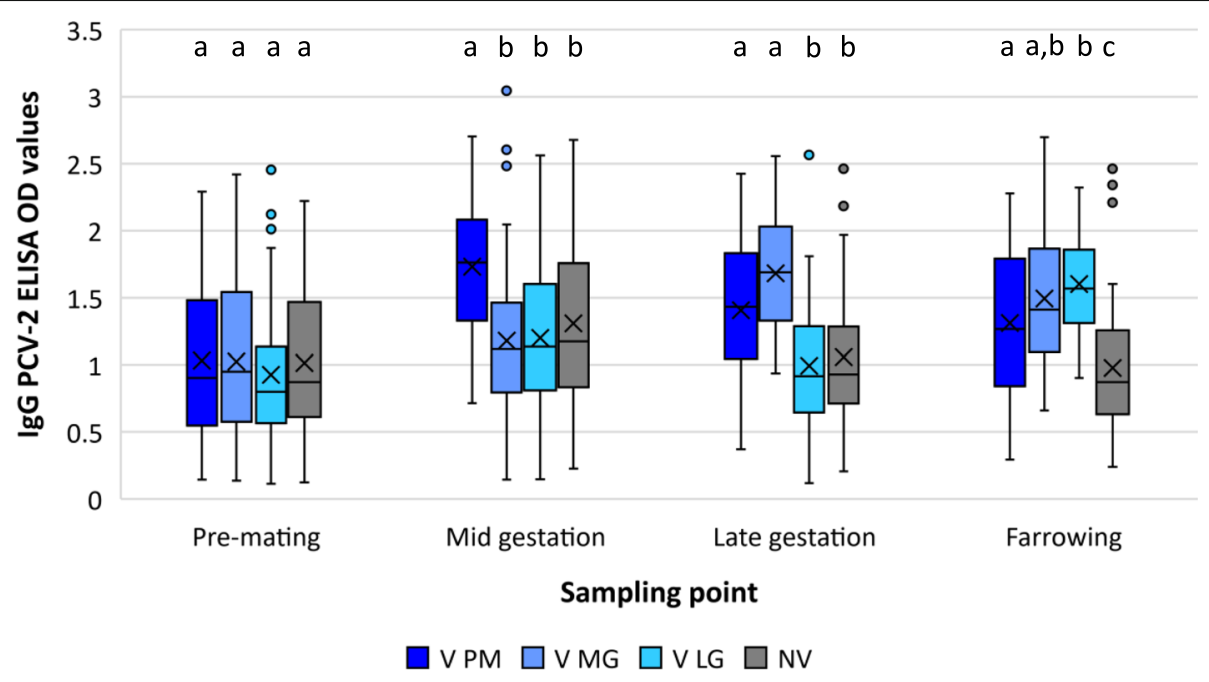

Fig. 1 PCV-2 IgG OD results (mean \pm SD) form sows' serum samples of the four experimental groups. VPM: vaccinated pre-mating; $V$ MG: vaccinated at mid gestation; V LG: vaccinated at late gestation; NV: non-vaccinated. Different letters indicate statistically significant differences $(p \leq 0.05)$ among experimental groups for a given sampling point

$\mathrm{mL}$ ) with $10^{3.9} \mathrm{PCV} 2$ copies $\left./ \mathrm{ml}\right)$. At farrowing sampling point, a lower $(p=0.01)$ proportion of positive PCV-2 qPCR in serum was detected in V sows (0 out of 172) compared to NV ones (2 out of 49).

PCV-2 DNA in serum samples from placental umbilical cord pools

Blood from 3 (ranging 1 to 4) porcine umbilical cords (PUCs) per sow were individually collected at farrowing to quantify virus in serum samples. All these samples were processed as a pool of 2-3 PUC sera/sow at farrowing ( $n=$ $171)$, except when only one PUC was collected $(n=13)$. The number of PCV-2 qPCR positive pools of PUCs was significantly lower $(p=0.01)$ in V sow groups $(12 / 142$ pools, 9\% [CI: $3.9-13.0 \%$ ]) compared to NV group (10/42 pools, 24\% [CI: 10.9-36.7\%]). When the comparison between each experimental group was performed, animals from V LG group had a significantly lower $(p=0.01)$ proportion of PCV-2 qPCR positive pools of PUCs (2/45 pools, $4 \%$ [CI: $1.6-10.5 \%])$ compared to NV sows (10/42 pools, $24 \%$ [CI: $10.9-36.7 \%])$. Additionally, a tendency $(p=0.08)$ in the proportion of PCV-2 qPCR positive pools of PUCs were noted in dams from $\mathrm{V}$ MG group (4/47 pools, 9\% [CI: $0.5-$ $16.5 \%])$ when compared to NV sows (10/42 pools, $24 \%$ [CI: 10.9-36.7\%]). Moreover, a lower $(p=0.01)$ PCV-2 load in PUC pools was observed in sows from the $\mathrm{V}$ groups (below

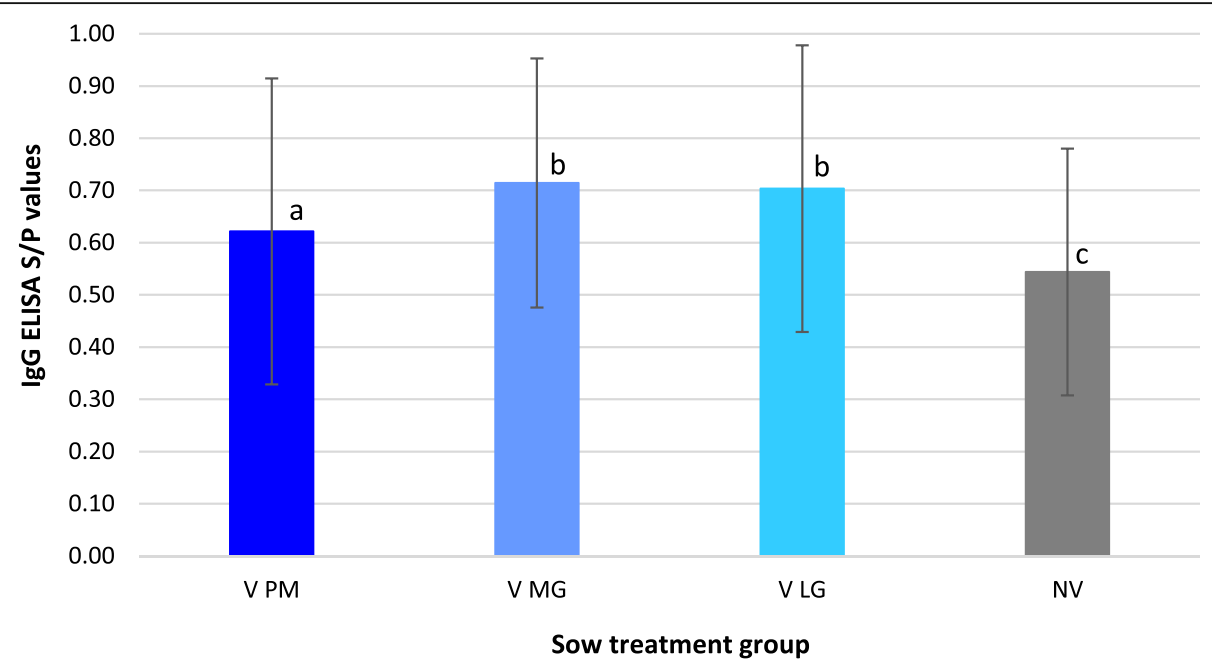

Fig. 2 PCV-2 IgG S/P values (mean \pm SD) from weaned piglets' serum samples of each experimental group. V PM: vaccinated pre-mating; $V$ MG: vaccinated at mid gestation; $V$ LG: vaccinated at late gestation; NV: non-vaccinated. Different letters indicate significant differences among experimental groups $(p \leq 0.05)$ 
Table 3 Proportion of PCV-2 qPCR positive sera in sows and $\mathrm{Cl}$ from $V$ and NV groups

\begin{tabular}{lllll}
\hline \multicolumn{5}{l}{ Sampling point } \\
\cline { 2 - 5 } & Pre-mating & Mid gestation & Late gestation & Farrowing \\
\hline V & $0 / 186(0.0 \%)$ & $1 / 178(0.6 \%)$ & $0 / 177(0.0 \%)$ & $0 / 172(0.0 \%)^{a}$ \\
& $\mathrm{Cl}: 0.0 \%$ & $\mathrm{Cl}:-0.5-1.7 \%$ & $\mathrm{Cl}: 0.0 \%$ & $\mathrm{Cl}: 0.0 \%$ \\
NV & $0 / 60(0.0 \%)$ & $0 / 52(0.0 \%)$ & $0 / 51(0.0 \%)$ & $2 / 49(4.1 \%)^{\mathrm{b}}$ \\
& $\mathrm{Cl}: 0.0 \%$ & $\mathrm{Cl}: 0.0 \%$ & $\mathrm{Cl}: 0.0 \%$ & $\mathrm{Cl}:-1.5-9.6 \%$ \\
\hline
\end{tabular}

Different letters in superscript indicate significant differences $(p \leq 0.05)$ among experimental groups

$\checkmark$ Vaccinated, NV Non-vaccinated

limit of detection [LOD] $\left[10^{0.42} \pm 10^{1.43}\right.$ PCV-2 genome copies/mL]) compared to NV ones (below LOD $\left[10^{1.12} \pm\right.$ $10^{2.11}$ PCV-2 genome copies $\left.\left./ \mathrm{mL}\right]\right)$. No statistically significant differences were observed in PCV-2 load in PUC pools when the comparison was done between each experimental group by separate.

\section{PCV-2 genotyping}

PCV-2 ORF2 from serum and PUC samples with some of the highest PCV-2 loads (between $10^{4.19}$ and $10^{8.06}$ PCV-2 genome copies $/ \mathrm{mL}$ ) were sequenced to ascertain the main PCV-2 genotype/s circulating in the farm. Specifically, one positive serum sample from the V PM group collected at mid gestation sampling point and 7 individual PUC samples recovered from 3 pools (three from the NV, two from the V MG and two from the V PM sow groups). The phylogenetic tree including the relationships among the ORF2 sequences determined in this study and reference strains is presented in Fig. 3. Genotype PCV-2b was found in the VPM sow serum sample from the mid gestation sampling point (MT572494 S 4525) and in 3 PUC from the same NV sow, all three with identical sequence (MT572495 PUC 3978). These two sequences showed 99, $54 \%$ of nucleotide identity between them. Genotype PCV2d was found in two PUC from a V PM sow (both with identical sequence, MT572497 PUC 4182) and in other two PUC from a V MG sow (also with the same sequence, MT572496 PUC 4035). These two sequences were identical between them as well.

\section{Discussion}

The present study deals with a poorly described topic such as the effects of sow vaccination against PCV-2 on

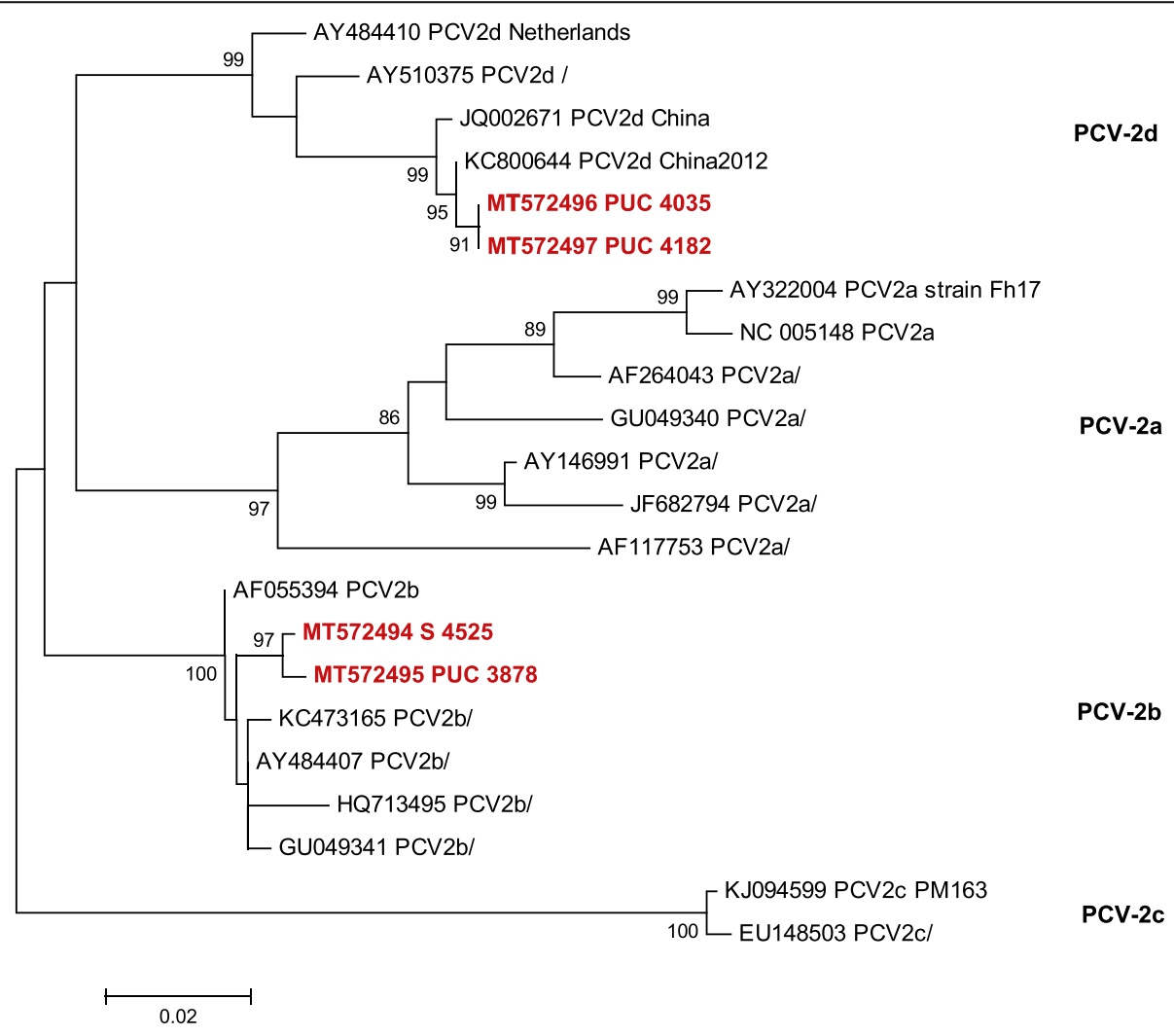

Fig. 3 Phylogenetic tree derived from PCV-2 capsid protein (ORF2) sequences. The tree was constructed by using Maximum-Likelihood method with 1000 bootstrap replicates. Bootstrap values higher than 70 are indicated. Sequences from this study are highlighted in red and labelled with the accession number + PUC (for PUC samples) or S (for sow sample) + sow number 
productive and infectious parameters of sows and their progeny. To accomplish this task, sows and gilts were vaccinated at three different reproductive periods (before mating, mid gestation and late gestation). When all the vaccinated sow groups were joined (independently of the moment of vaccine application), mimicking a blanket fashion vaccination strategy, significant improvement of productive parameters in terms of piglets' weight at birth and at weaning and cross-fostering practice reduction were achieved. Moreover, a significant reduction in the proportion of PCV-2 infected sows and their viral loads at farrowing and in PUC were also observed when compared to NV sows, although a low PCV-2 infection pressure was detected. When the period of vaccine application was considered, a tendency in reduction of mummies in the V PM group compared to $\mathrm{NV}$ one was observed.

Few published studies describe the benefits of sow vaccination on reproductive parameters under field conditions. This is probably due to the low frequency of reproductive disorders associated with PCV-2 [26], and their rather unknown impact. Currently, only five peerreviewed published studies recorded reproductive parameters in vaccinated sow farms. In one study [22], dams were vaccinated against PCV-2 at 4 and 2 weeks before artificial insemination and 4 weeks pre-partum. In another one [16], sows were vaccinated 1 week prior to mating. In the third one [26], PCV-2 sow vaccination was implemented for 3 years; dams were vaccinated at 6 and 3 weeks before farrowing in the first reproductive cycle and boosted in the following reproductive cycles at 3 weeks before farrowing. In the fourth study [13], dams were immunized against PCV-2 at 6 and 3 weeks prefarrowing on the first cycle and sows received a boost 2 weeks pre-farrowing on the second cycle. Finally, in the last one [27], three groups of sows were PCV-2 vaccinated 1 day after weaning, 28 days after weaning and non-vaccinated, respectively. In the present study, in comparison with the abovementioned works, the sow vaccination scheme considered PCV-2 vaccination at different reproductive time points in the same herd, resembling a blanket fashion vaccination strategy.

In the present study, piglets from $\mathrm{V}$ sows showed a significantly higher mean birth weight. Among all vaccination groups, the highest body weights were obtained in piglets coming from V MG and V LG groups. Considering the short period between vaccination at late gestation and the delivery, the difference in weight between piglets from V LG and NV groups was unexpected. This result, however, would be similar to the one obtained in one study in which sows were also vaccinated at late gestation [26]. Moreover, the weight of weaned piglets (at 3 weeks of age approximately) coming from $\mathrm{V}$ sows was higher compared to those from NV dams. These results are in contrast with the ones of Fraile et al. [16], where sows were vaccinated pre-mating and no differences were observed in weaned piglet weight at 4 weeks of age. Reasons for such differences may be attributable to the different vaccine product or schedule used and/or lack of power due to the limited sample size of the study. Moreover, there are many inter-farm factors (animal genetics, farm facilities, management practices, treatments, nutrition and vaccination schedule) that may influence the vaccination outcome.

Piglets coming from $\mathrm{V}$ sows were significantly less cross-fostered compared to the NV group; more specifically, significantly less cross-fostering was performed in VPM and V MG dams compared to the NV group. Also, a tendency to practice less cross-fostering in piglets from V MG dams was noted compared to that in V LG sows. Cross-fostering is a practice frequently used to increase piglet survival and to organize litters with uniform body weight [28]. However, biosecurity procedures recommend minimizing the number of cross-fostered animals [29]; therefore, reduction of this practice may help diminishing PCV-2 transmission among piglets.

A tendency of a lower proportion of mummies was observed in the V PM sow group compared with the NV group. Considering that mummification is an outcome of late reproductive problems [30], the potential benefits of PCV-2 vaccination at pre-mating on mummies reduction was expected. This result is in contrast with Kurmann et al. [22] and Sibila et al. [24], where sows were vaccinated pre-mating, and with Oliver-Ferrando et al. [13], where sows were vaccinated at mid-late gestation. Further studies with a higher number of tested sows would be needed to confirm the data obtained herein.

In relation to stillborn, no statistical differences were observed in the current study, in accordance with Cybulski et al. study [27]. Oliver-Ferrando et al. [13] found an inconsistent situation, where a higher number of stillbirths/litter in the $\mathrm{V}$ group was observed in the first reproductive cycle but not in the second one. Nevertheless, proportions of stillborn detected in the present study and in Oliver-Ferrando et al. [13] are aligned with regular values expected in the average Spanish pig farm (8.6\%) according to national records (www.bdporc.irta.es).

Although Oliver-Ferrando et al. [13] and Pejsak et al. [26] reported an improvement in number of liveborn piglets, in the present case only a positive (numerically, but non-significant) effect was obtained similar to the study of Kurmann et al. [22] and in 28 days after weaning vaccination group from Cybulski et al. study [27].

In addition, no significant differences in the proportion of abortions were detected in the present study similarly to results obtained in Kurmann et al. study [22]. Considering the low frequency of abortions detected in the present study, a larger sample size would be necessary to 
analyse this parameter and determine their effect. Nevertheless, the design of our study was not within the scope of detecting the presence of significant differences for this latter parameter.

Similarly, Pejsak et al. [26] and Oliver-Ferrando et al. [13] detected a higher number of weaned piglets/litter (being only statistically significant in Pejsak) in V dams compared to NV dams, respectively. These two latter studies indicated that the repeated use of PCV-2 sow vaccination can improve reproductive parameters. So, these positive effects (piglets born alive and weaned piglets/litter) may probably be more evident after several gestational cycles vaccinating the sows against $\mathrm{PCV}-2$ rather than one single vaccination of sows as in the present study.

The antibody profile from sows immunized against PCV-2 revealed seroconversion after each vaccination, conferring a stronger herd immunity against PCV-2 compared to the NV $[10,13,22,24]$. Besides, the NV group maintained low ELISA OD values during all gestation period. In this sense, despite sow infection remained low or non-detectable in all studied groups during the gestation period, no $\mathrm{V}$ sows were found infected at farrowing while $4 \%$ of $\mathrm{NV}$ ones were $\mathrm{qPCR}$ positive. $\mathrm{Al}$ though significant differences at the farrowing period in terms of percentage of viraemic sows was detected, the number of PCV-2 qPCR positive sera in sows was low. These results, however, should not be considered surprising since the number of infected sows tend to be low in most farms where subclinical infection is taking place $[8,13,31,32]$; moreover, batch differences may also account for certain variability. Therefore, further studies would be desirable to further confirm this finding.

The virological results obtained in the study were in fairly contrast with those obtained in the screening prior to the start of the study, where PCV-2 DNA was detected in serum samples from 18 out of 30 clinically healthy sows. Moreover, PCV-2 genome was also detected in 24 out of 30 PUCs from the same sows. These initial results would fit well with those observed by other research groups in some PCV-2-SI farms in absence of vaccination [33]. It is very likely that differences on percentage of infected sows among batches and the PCV-2 vaccination in $3 / 4$ of the studied groups could explain the variability and reduction of the PCV-2 infection pressure within the same farm when the large study was carried out. It is speculated that the reduction of the PCV-2 infection pressure probably caused a reduction of transplacental transmission of PCV-2 to foetuses, evidenced by the lower proportion of PUC PCV-2 qPCR positive samples and viral load detected compared to the farm previous screening.

The higher antibody levels of $\mathrm{V}$ sows than $\mathrm{NV}$ ones at farrowing suggests a higher transfer of maternally derived antibodies (MDA) to piglets of $\mathrm{V}$ sows via colostrum as also described [16, 22, 34]. This scenario should place piglets from $\mathrm{V}$ sows in a better immune position to counteract PCV-2 infection at early ages [16]. As expected, the highest MDA transfer was observed in weaned piglets from V MG and V LG groups, followed by V PM. On the other hand, considering that all piglets were vaccinated at 3 weeks of age against PCV-2, certain concerns regarding MDA interference with vaccination could arise. Although in this study MDA interference with pig vaccination was not explored, several studies have reported evidence of such interference with vaccine humoral immune response [16, 35-38]. However, the efficacy of the same vaccine used in this study has not shown to be jeopardized by high values of MDA [39].

Two PCV-2 genotypes, PCV-2b and PCV-2d, circulated in the herd, being the most prevalent ones in the field worldwide $[40,41]$. The co-circulation of two or more PCV-2 genotypes in the same farm is not unusual [4244]. Current vaccines based on PCV-2a strains appear to be able to cope with major circulating strains worldwide due to cross-protection among genotypes [3, 18-20].

PCV2 vaccines are the most sold preventive product in the porcine industry and one of the biological products in swine with highest return of inversion [15]. Besides, the combined vaccination of sows and piglets is an increasing practice since provides the optimal performance in animals $[16,45]$, and although there is little information about gilt/sow immunization, vaccination of pigs and sows has been estimated cost-efficient [15]. However, each farm should be analysed case by case to study the cost /benefit of PCV-2 vaccination [46].

\section{Conclusions}

Vaccination of the breeding herd (gilts and sows) against PCV-2, mimicking a blanket fashion schedule in a subclinical infection scenario, improved immune status of dams and the progeny against the virus and reduced virus circulation at farrowing in sows and vertical infection to foetuses, although a low infectious pressure was detected during the study. PCV-2 sow vaccination also improved piglets' weight at birth and at weaning and reduced cross-fostering practice. Also, a tendency in reduction of mummies from VPM group compared to NV was observed. Due to the limited PCV-2 circulation detected in the dams during the present exploratory study, the impact of $\mathrm{PCV}-2$ vaccination on the productivity was considered of low impact. Further studies should be needed to confirm the currently obtained results.

\section{Materials and methods}

\section{Farm selection}

Inclusion criteria for farm selection were: a) sows/gilts housed in a single conventional farm (site I), b) no PCV- 
2 vaccination schedule in gilts/sows, c) allowance of controlled cross-fostering practices, and d) evidence of PCV-2 infection by means of viral genome detection in sows and PUCs in site I. Indeed, prior to the start of the study, PCV-2 DNA was detected in serum samples from 18 out of $30\left(60 \%\right.$, viral load range $10^{3.50}$ and $10^{7.91}$ genome copies $/ \mathrm{mL}$ ) clinically healthy sows from different parity number and in 24 out of $30(80 \%$, viral load range $10^{3.50}$ and $10^{7.06}$ genome copies/ml) PUCs from the same sows, indicating a PCV-2-SI scenario. Inclusion criteria for gilts/sows selection were: a) healthy animals, b) not pregnant, c) from the same genetic line, d) of all parities (gilts, primiparous and multiparous).

The study was conducted in a two-site commercial farm located in Catalonia (Spain). The farm had 1400 sows (including gilts) and used a weekly farrowing batch system; piglet weaning was performed at 25 days of age approximately. The farm was Mycoplasma hyopneumoniae positive, Porcine reproductive and respiratory syndrome virus (PRRSV) positive stable, and negative for Aujeszky's disease virus. Gilts and sows were crossbred (Duroc x Landrace) and were artificially inseminated with Pietrain boar semen. The vaccination routine of the farm included gilt and sow immunization against PRRSV, Porcine parvovirus, Erysipelothrix rhusiopathiae, Escherichia coli and Clostridium perfringens. Piglets were vaccinated against PCV-2 and Mycoplasma hyopneumoniae before weaning.

\section{Study design}

The present study was a parallel group, randomised and controlled trial. The study was unmasked for personnel involved in study design and monitoring, vaccine dispensation and for personnel involved in body weight and sample collection, whereas it was masked for farm personnel (routine management, daily observation and routine reproductive data recording) as well as for laboratory technicians. Study design is summarized in Fig. 4. Sows were bled before mating and tested for PCV-2 IgG and IgM ELISAs. Animals were randomly allocated into 4 different treatment groups blocking by parity (from 0 to 8 ) and OD values for PCV-2 IgG and PCV-2 IgM. A total of 288 healthy sows were selected through six consecutive breeding batches and distributed in the following treatments groups: vaccination of 73 at pre-mating (PM), 72 at mid gestation (MG), 73 at late gestation (LG) and 70 were kept as NV sows. These three specific immunization times were chosen to mimic a blanket vaccination fashion, which is performed in sows at all physiological status at a given time point. Gestation was monitored until farrowing and then their piglets were followed up until weaning. Sows from all treatment groups were housed comingled during the study (in same pens when they were housed in groups, and in same room when they were individualized). Cross-fostering of piglets was only allowed among sows of the same experimental group.

All sows included in the study were injected (with phosphate buffered saline $[\mathrm{PBS}]$ or PCV-2 vaccine) three times before farrowing. Sows were vaccinated intramuscularly (neck muscle) with $1 \mathrm{~mL}$ of PCV-2 Ingelvac Circoflex $^{\circ}$ or PBS. Blood samples from sows were collected at the three vaccine/PBS application times as well as at farrowing. Obtained sera were tested for PCV-2 IgG and

\begin{tabular}{|c|c|}
\hline Pre-mating & $\begin{array}{l}\text {-PCV-2 qPCR and IgG/IgM ELISAs from sow sera samples } \\
\text { - Randomly allocated in V PM, V MG, V LG or NV } \\
\text {-PBS (V MG, V LG and NV) or PCV-2 vaccine (V PM) administration }\end{array}$ \\
\hline $\begin{array}{l}\text { Mid gestation } \\
\text { (42-49 days post AI) }\end{array}$ & $\begin{array}{l}\text {-PCV-2 qPCR and IgG/IgM ELISAs from sow sera samples } \\
\text {-PBS (V PM, V LG and NV) or PCV-2 vaccine (V MG) administration }\end{array}$ \\
\hline $\begin{array}{l}\text { Late gestation } \\
\text { (86-93 days post } \mathrm{AI})\end{array}$ & $\begin{array}{l}\text {-PCV-2 qPCR and IgG/IgM ELISAs from sow sera samples } \\
\text {-PBS (V PM, V MG and NV) or PCV-2 vaccine (V LG) administration }\end{array}$ \\
\hline Farrowing & $\begin{array}{l}\text {-PCV-2 qPCR and IgG/IgM ELISAs from sow sera samples } \\
\text {-PCV-2 qPCR from 1-4 PUC/sow sera samples } \\
\text {-Productive parameters recorded }\end{array}$ \\
\hline $\begin{array}{l}\text { Piglets Weaning } \\
\text { (25 days of age) }\end{array}$ & -PCV-2 IgG ELISA from 4-6 piglets/sow sera samples \\
\hline
\end{tabular}

Fig. 4 Experimental study design, including sampling time points and PCV-2 vaccine/PBS application timing. V PM: vaccinated at pre-mating; V MG: vaccinated at mid gestation; V LG: vaccinated at late gestation; NV: non-vaccinated; Al: artificial insemination; PCV-2 vaccine: 1 mL of PCV-2 Ingelvac Circoflex ${ }^{\oplus}$; PBS: phosphate buffer saline 
IgM antibodies using a commercial ELISA assay and to quantify virus using a qPCR assay. At pre-mating sampling point, PCV-2 IgG and IgM ELISA assay was performed in 288 sow sera to randomize the sows in 4 experimental groups. ELISA assay from mid gestation, late gestation and farrowing sampling points and qPCR assay from the fourth sampling points were performed only in those artificially inseminated sows (Additional file 1). Blood from 3 (ranging 1 to 4) PUCs per sow were individually collected at farrowing to quantify virus in serum samples using the qPCR assay. In order to minimize PCV-2 environmental contamination, gloves were changed, and scissors were disinfected with ethanol for each PUC sampling. Additionally, productive parameters from gilts/sows and piglets were recorded (described in section 7). Moreover, at weaning, sera samples from 4 to 6 randomly selected piglets per each sow were taken and used to detect PCV-2 antibodies using an ELISA test.

Once in the laboratory, blood samples were centrifuged at $2500 \mathrm{rpm}(1300 \mathrm{~g})$ during $10 \mathrm{~min}$ at $4{ }^{\circ} \mathrm{C}$ to obtain sera. All sera were stored at $-20^{\circ} \mathrm{C}$ until testing.

\section{DNA extraction and qPCR}

Presence of PCV-2 DNA by qPCR was assessed in the serum samples from sows and PUCs. All these samples were processed by pools. Indeed, pools from 2 to 3 sow serum samples at each sampling point and pools of 2-3 PUC sera per sow at farrowing (except when only one PUC was collected) were created. When a pool from sow sera was $\mathrm{qPCR}$ positive, individual serum samples were tested by qPCR following the same protocol.

DNA was extracted from $200 \mu \mathrm{L}$ of serum (from sows) or pool by using the MagMAX ${ }^{\text {sin }}$ Pathogen RNA/DNA Kit (Thermo Fischer Scientific Baltics. Vilnius, Lithuania) following the manufacturer's instructions. To quantify the PCV-2 DNA in serum samples, a qPCR assay (LSI VetMAX $^{\text {mi }}$ Porcine Circovirus Type 2-Quantification, Applied Biosystems, Lisseu, France) was performed. Each extraction and GPCR plate included negative controls (diethylpyrocarbonate [DEPC]-treated water) and each sample reaction had an internal positive control to monitor DNA extraction and amplification procedures.

PCV-2 qPCR results were transformed as follows:

- Undetermined results and those below LOD $\left(\mathrm{LOD}=10^{3.50} \mathrm{PCV}-2\right.$ genome copies $/ \mathrm{mL}$ ) were transformed as $\log _{10}(0+1)$.

- Results between LOD and LOQ (LOQ $=10^{4.00}$ PCV2 genome copies $/ \mathrm{mL}$ ) were transformed following the method proposed by Croghan et al. [47], where the result was calculated as $\log _{10}((\mathrm{LOQ} / \sqrt{ } 2)+1)$. Therefore, the imputed value was $\log _{10}(7071+1)$.
- Results over LOQ were transformed as $\log _{10}(\mathrm{PCV}-2$ genome copies $/ \mathrm{mL}+1)$.

\section{PCV-2 antibody detection by ELISA}

PCV-2 antibodies in sows were detected at the three vaccine/PBS application times as well as at farrowing using the ELISA kit Ingezim Circo IgG/IgM 11.PCV.K2 ${ }^{\circ}$ assay (Ingenasa, Madrid, Spain). ELISA results were expressed as mean OD ( \pm SD) according to the kit instructions.

PCV-2 antibodies in piglets at weaning were detected using the ELISA kit Ingezim Circo IgG 11.PCV.K1 ${ }^{\circ}$ assay (Ingenasa, Madrid, Spain). Mean positive cut-off was established as OD of negative control +0.25$)$. ELISA results from piglets were expressed as S/P ratio (OD of sample / OD of positive control for each ELISA plate) following the manufacturer's recommendations.

\section{PCV-2 ORF2 amplification and sequencing}

Capsid protein gene (ORF2) was sequenced from PCV-2 qPCR positive sow serum and PUC samples to determine the PCV-2 genotype/s circulating in the farm. DNA was extracted from serum samples by using the $\operatorname{MagMax}^{\mathrm{mm}}$ Pathogen RNA/DNA Kit (Thermo Fischer Scientific Baltics. Vilnius, Lithuania) following the manufacturer's instructions.

PCV-2 Cap gene was amplified from nucleotide 1050 to 1735 (PCV-2 genome; GenBank Accession Number: AY181948) using the primers PCV-2all_F (5' GGGTCT TTAAGATTAAATYC $3^{\prime}$ ) and PCV-2all_R (5' ATGA CGTATCCAAGGAG 3') [48]. PCR was performed in a $25 \mu \mathrm{L}$ reaction containing $5 \mu \mathrm{L}$ of PCR Promega buffer, $2.5 \mu \mathrm{L}$ of $25 \mathrm{Mm} \mathrm{MgCl}_{2}, 1.25 \mu \mathrm{L}$ of each primer at 10 $\mathrm{pmol} / \mu \mathrm{L}, 1 \mu \mathrm{L}$ of $5 \mathrm{mM}$ dNTPs, $0.15 \mathrm{U}$ of Taq DNA polymerase, $11.35 \mu \mathrm{L}$ of DEPC-treated water and $2.5 \mu \mathrm{L}$ of extracted DNA. The PCR was performed with the following program: denaturation of $5 \mathrm{~min}$ at $94{ }^{\circ} \mathrm{C}, 40 \mathrm{cy}$ cles of $30 \mathrm{~s}$ at $95^{\circ} \mathrm{C}$ for denaturation, $30 \mathrm{~s}$ at $53^{\circ} \mathrm{C}$ for primer annealing and $40 \mathrm{~s}$ at $72{ }^{\circ} \mathrm{C}$ for elongation, with a final elongation of $7 \mathrm{~min}$ at $72^{\circ} \mathrm{C}$. Amplified DNA was confirmed by electrophoresis gel with $2 \%$ agarose.

NucleoSpin Gel and PCR Clean-up kit (MachereyNagel, GmbH \& Co. KG, Dueren, Germany) was used to purify the PCR product. BigDye Terminator v3.1 Cycle Sequencing Kit (Applied Biosystems, Foster City, CA, USA) and $3130 \times 1$ Genetic Analyser (Applied Biosystems, Ohio, USA) was used to perform the sequencing reaction and the analysis, respectively [48]. Sequences were edited and assembled by using ChromasPro Version 2.1.8 (Technelysium). The sequences obtained were submitted to the GenBank with the following accession numbers MT572494-MT572497). 


\section{PCV-2 capsid ProteinG (ORF2) phylogenetic and sequence analysis}

To genotype the PCV-2 sequences obtained, an alignment with 18 representative sequences from genotypes PCV-2a, b, c and d was carried out with Clustal Omega (EMBL-EBI). The phylogenetic tree was created by using the Maximum Likelihood method included in Mega- $\mathrm{X}$ software [49]. The best substitution model according with the Bayesian information criterion was the Hasegawa-Kishino-Yano model, with a discrete Gamma distribution. Bootstrap resampling test was carried out with 1000 replicates. Bootstrap values higher than 70 were indicated in the constructed phylogenetic tree.

\section{Statistical analyses}

Statistical analyses were carried out using the software NCSS (Kaysville, Utah, USA). Comparisons were performed in two ways: 1) all V groups (mimicking a blanket fashion PCV-2 vaccination) versus the NV group, and 2) all experimental groups among them.

When comparison was performed between $\mathrm{V}$ and NV groups Mann-Whitney $U$ test was used to total born piglets per sow, live born piglets per sow, weaned piglets per sow, weaning-to-mate interval, weaning-tofecundation interval, PCV-2 viral load in sera of sows as well as viral load in PUC. Chi-square test was used to compare proportions of abortions, mummified fetuses, stillbirth piglets, dead suckling piglets, cross-fostered piglets, as well as of viraemic sows and PUC. The T test was used to analyse birth and weaning body weights.

When comparison was performed among all experimental groups, Kruskal Wallis test (including Bonferroni test for multiple comparison) was used to analyse total born piglets per sow, live born piglets per sow, weaned piglets per sow, weaning-to-mate interval, weaning-tofecundation interval, PCV-2 ELISA antibody values in sow and piglets' serum samples and viral load in sera of sows and PUCs. Serological parameters from sows were analysed performing only the comparison among experimental groups to assess the serological effect of each vaccination. Chi-square or Fisher's Extact test was used to compare proportion of abortions, mummified piglets, stillbirth piglets, dead suckling piglets, cross-fostered piglets, as well as of viraemic sows and PUCs. Moreover, ANOVA (including Tukey-Kramer multiple comparison test) was used to compare birth and weaning body weights.

The significance level $(\alpha)$ was set at $p \leq 0.05$, whereas statistical tendencies were reported when $p \leq 0.10$.

\section{Abbreviations}

DEPC: Diethylpyrocarbonate; ELISA: Enzyme-linked immunosorbent assay; LOD: Limit of detection; LOQ: Limit of quantification; MDA: Maternally derived antibodies; NV: Non-vaccinated; OD: Optical density; PBS: Phosphate buffered saline; PCV-2: Porcine circovirus 2; PRRSV: Porcine reproductive and respiratory syndrome virus; PUC: Placental umbilical cord; qPCR: Real time quantitative polymerase chain reaction; SD: Standard Deviation; V LG: Vaccinated at late gestation; V MG: Vaccinated at mid gestation; V PM: Vaccination at pre-mating

\section{Supplementary Information}

The online version contains supplementary material available at https://doi. org/10.1186/s40813-021-00213-2.

Additional file 1. Number of animals analysed at each sampling point.

\section{Acknowledgments}

The authors would like to thank to the farm animal caretakers and veterinarian for their willingness to collaborate in the study.

\section{Authors' contributions}

JS, MS and SL designed the study; SL and PP coordinated the study execution and performed the statistical analyses; MS coordinated the sample processing; $\mathrm{DP}, \mathrm{RC}$, and $\mathrm{RL}$ contributed to the sampling and study execution. AML and EH processed all the samples collected. JIN performed the PCV-2 genotyping; PP drafted the manuscript; MS, JIN, JS and SL revised the manuscript. All the authors read and approved the published version of the manuscript.

\section{Funding}

This research was awarded in the European Porcine Circovirus (PCV-2) Research Award by Boehringer Ingelheim.

\section{Availability of data and materials}

The datasets used and/or analysed during the current study are available from the corresponding author on reasonable request.

\section{Declarations}

Ethics approval and consent to participate

The present study was approved by the Ethics Committee for Animal Experimentation from the Universitat Autònoma de Barcelona and the Animal Experimentation Commission from the local government (Dpt. de Medi Ambient i Habitatge from the Generalitat de Catalunya; Reference 5796).

Consent for publication

Not applicable.

\section{Competing interests}

The authors declare that they have no competing interests.

\section{Author details}

${ }^{1}$ IRTA, Centre de Recerca en Sanitat Animal (CReSA, IRTA-UAB), Campus de la Universitat Autònoma de Barcelona, 08193 Bellaterra, Spain. ${ }^{2} \mathrm{OIE}$ Collaborating Centre for the Research and Control of Emerging and Re-emerging Swine Diseases in Europe (IRTA-CReSA), Bellaterra, Spain. ${ }^{3} U A B$, Centre de Recerca en Sanitat Animal (CReSA, IRTA- UAB), Campus de la Universitat Autònoma de Barcelona, 08193 Bellaterra, Spain. ${ }^{4}$ Departament de Sanitat i Anatomia Animals, Facultat de Veterinària, UAB, 08193 Bellaterra, Spain.

Received: 19 February 2021 Accepted: 10 April 2021

Published online: 26 April 2021

\section{References}

1. Rosario K, Breitbart M, Harrach B, Segalés J, Delwart E, Biagini P, et al. Revisiting the taxonomy of the family Circoviridae: establishment of the genus Cyclovirus and removal of the genus Gyrovirus. Arch Virol. 2017; 162(5):1447-63. https://doi.org/10.1007/s00705-017-3247-y.

2. Kekarainen T, McCullough K, Fort M, Fossum C, Segalés J, Allan GM. Immune responses and vaccine-induced immunity against Porcine circovirus type 2. Vet Immunol Immunopathol. 2010;136(3-4):185-93. https://doi.org/10.1016/ j.vetimm.2010.03.025. 
3. Segalés J, Kekarainen T, Cortey M. The natural history of porcine circovirus type 2: from an inoffensive virus to a devastating swine disease? Vet Microbiol. 2013;165(1-2):13-20. https://doi.org/10.1016/j.vetmic.2012.12.033.

4. Sibila M, Calsamiglia $M$, Segalés J, Blanchard $P$, Badiella $L$, Le Dimna $M$, et al. Use of a polymerase chain reaction assay and an ELISA to monitor porcine circovirus type 2 infection in pigs from farms with and without postweaning multisystemic wasting syndrome. Am J Vet Res. 2004;65(1):8892. https://doi.org/10.2460/ajvr.2004.65.88.

5. Rodríguez-Arrioja GM, Segalés J, Calsamiglia M, Resendes AR, Balasch M, Plana-Duran J, et al. Dynamics of porcine circovirus type 2 infection in a herd of pigs with postweaning multisystemic wasting syndrome. Am J Vet Res. 2002;63(3):354-7. https://doi.org/10.2460/ajvr.2002.63.354.

6. Rose N, Larour G, Le Diguerher G, Eveno E, Jolly JP, Blanchard P, et al. Risk factors for porcine post-weaning multisystemic wasting syndrome (PMWS) in 149 French farrow-to-finish herds. Prev Vet Med. 2003;61(3):209-25. https://doi.org/10.1016/j.prevetmed.2003.07.003.

7. Segalés J. Porcine circovirus type 2 (PCV2) infections: clinical signs, pathology and laboratory diagnosis. Virus Res. 2012;164(1-2):10-9. https:// doi.org/10.1016/j.virusres.2011.10.007.

8. Eddicks M, Koeppen M, Willi S, Fux R, Reese S, Sutter G, et al. Low prevalence of porcine circovirus type 2 infections in farrowing sows and corresponding pre-suckling piglets in southern German pig farms. Vet Microbiol. 2016;187:70-4. https://doi.org/10.1016/j.vetmic.2016.03.010.

9. Gerber PF, Garrocho FM, Lana AM, Lobato Zl. Fetal infections and antibody profiles in pigs naturally infected with porcine circovirus type 2 (PCV2). Can J Vet Res. 2012;76(1):38-44.

10. Hemann M, Beach NM, Meng XJ, Wang C, Halbur PG, Opriessnig T. A liveattenuated and an inactivated chimeric porcine circovirus (PCV)1-2 vaccine are both effective at inducing a humoral immune response and reducing PCV2 viremia and intrauterine infection in female swine of breeding age. Can J Vet Res. 2014;78(1):8-16.

11. Madson DM, Patterson AR, Ramamoorthy S, Pal N, Meng XJ, Opriessnig T. Effect of porcine circovirus type 2 (PCV2) vaccination of the dam on PCV2 replication in utero. Clin Vaccine Immunol. 2009;16(6):830-4. https://doi. org/10.1128/CVI.00455-08.

12. Nauwynck HJ, Sanchez R, Meerts P, Lefebvre DJ, Saha D, Huang L, et al. Cell tropism and entry of porcine circovirus 2. Virus Res. 2012;164(1-2):43-5. https://doi.org/10.1016/j.virusres.2011.11.003.

13. Oliver-Ferrando S, Segalés J, López-Soria S, Callén A, Merdy O, Joisel F, et al. Exploratory field study on the effect of Porcine circovirus 2 (PCV2) sow vaccination on serological, virological and reproductive parameters in a PCV2 subclinically infected sow herd. BMC Vet Res. 2018;14(1):130. https:// doi.org/10.1186/s12917-018-1452-x

14. Lopez-Rodriguez A, Dewulf J, Meyns T, Del-Pozo-Sacristán R, Andreoni C, Goubier A, et al. Effect of sow vaccination against porcine circovirus type 2 (PCV2) on virological profiles in herds with or without PCV2 systemic disease. Can Vet J. 2016;57(6):619-28.

15. Segalés J. Best practice and future challenges for vaccination against porcine circovirus type 2. Expert Rev Vaccines. 2015;14(3):473-87. https://doi. org/10.1586/14760584.2015.983084.

16. Fraile L, Sibila M, Nofrarías M, López-Jimenez R, Huerta E, Llorens A, et al. Effect of sow and piglet porcine circovirus type 2 (PCV2) vaccination on piglet mortality, viraemia, antibody titre and production parameters. Vet Microbiol. 2012;161(1-2):229-34. https://doi.org/10.1016/ j.vetmic.2012.07.021.

17. Oh Y, Seo HW, Park C, Chae C. Comparison of sow and/or piglet vaccination of 3 commercial porcine circovirus type 2 (PCV2) single-dose vaccines on pigs under experimental PCV2 challenge. Vet Microbiol. 2014;172(3-4):37180. https://doi.org/10.1016/j.vetmic.2014.05.028.

18. Opriessnig T, Gerber PF, Xiao CT, Halbur PG, Matzinger SR, Meng XJ. Commercial PCV2a based vaccines are effective in protecting naturally PCV2b-infected finisher pigs against experimental challenge with a 2012 mutant PCV2. Vaccine. 2014;32(34):4342-8. https://doi.org/10.1016/j.va ccine.2014.06.004

19. Fort M, Sibila M, Allepuz A, Mateu E, Roerink F, Segalés J. Porcine circovirus type 2 (PCV2) vaccination of conventional pigs prevents viremia against PCV2 isolates of different genotypes and geographic origins. Vaccine. 2008; 26(8):1063-71. https://doi.org/10.1016/j.vaccine.2007.12.019.

20. Franzo G, Segalés J. Porcine circovirus 2 genotypes, immunity and vaccines: multiple genotypes but one single serotype. Pathogens. 2020;9(12):1049. https://doi.org/10.3390/pathogens9121049.
21. Gerber PF, Garrocho FM, Lana AM, Lobato ZI. Serum antibodies and shedding of infectious porcine circovirus 2 into colostrum and milk of vaccinated and unvaccinated naturally infected sows. Vet J. 2011;188(2): 240-2. https://doi.org/10.1016/j.tvjl.2010.03.023.

22. Kurmann J, Sydler T, Brugnera E, Buergi E, Haessig M, Suter M, et al. Vaccination of dams increases antibody titer and improves growth parameters in finisher pigs subclinically infected with porcine circovirus type 2. Clin Vaccine Immunol. 2011;18(10):1644-9. https://doi.org/10.1128/CVI.051 83-11.

23. O'Neill KC, Hemann M, Giménez-Lirola LG, Halbur PG, Opriessnig T. Vaccination of sows reduces the prevalence of PCV-2 viraemia in their piglets under field conditions. Vet Rec. 2012;171(17):425. https://doi.org/1 $0.1136 / v r .100660$

24. Sibila M, Fraile L, Ticó G, López-Soria S, Nofrarías M, Huerta E, et al. Humoral response and colostral antibody transfer following 'one-dose' pre-mating vaccination of sows against porcine circovirus type-2. Vet J. 2013;197(3):8813. https://doi.org/10.1016/j.tvjl.2013.04.014.

25. Opriessnig T, Patterson AR, Madson DM, Pal N, Ramamoorthy S, Meng XJ, et al. Comparison of the effectiveness of passive (dam) versus active (piglet) immunization against porcine circovirus type 2 (PCV2) and impact of passively derived PCV2 vaccine-induced immunity on vaccination. Vet Microbiol. 2010;142(3-4):177-83. https://doi.org/10.1016/j.vetmic.2009.09.056.

26. Pejsak Z, Kusior G, Pomorska-Mól M, Podgórska K. Influence of long-term vaccination of a breeding herd of pigs against PCV2 on reproductive parameters. Pol J Vet Sci. 2012;15(1):37-42. https://doi.org/10.2478/v10181011-0111-y.

27. Cybulski P, Woźniak A, Podgórska K, Stadejek T. Vaccination of sows against porcine circovirus type 2 (PCV2) in a subclinically infected herd does not impact reproductive performance. Agriculture. 2020;10(12):639. https://doi. org/10.3390/agriculture10120639.

28. Wattanaphansak S, Luengyosluechakul S, Larriestra A, Deen J. The impact of cross-fostering on swine production. Thai J Vet Med. 2002;32:101-6.

29. Rose N, Opriessnig T, Grasland B, Jestin A. Epidemiology and transmission of porcine circovirus type 2 (PCV2). Virus Res. 2012;164(1-2):78-89. https://doi. org/10.1016/j.virusres.2011.12.002.

30. Madson DM, Patterson AR, Ramamoorthy S, Pal N, Meng XJ, Opriessnig T. Reproductive failure experimentally induced in sows via artificial insemination with semen spiked with porcine circovirus type 2. Vet Pathol. 2009;46(4):707-16. https://doi.org/10.1354/vp.08-VP-0234-O-FL.

31. Eddicks M, Beuter B, Stuhldreier R, Nolte T, Reese $S$, Sutter $G$, et al. Crosssectional study on viraemia and shedding of porcine circovirus type 2 in a subclinically infected multiplier sow herd. Vet Rec. 2019;184(6):189. https:// doi.org/10.1136/vr.105069.

32. Dieste-Pérez L, van Nes A, van Maanen K, Duinhof T, Tobias T. The prevalence of PCV2 viremia in newborn piglets on four endemically infected Dutch sow farms is very low. Prev Vet Med. 2018;153:42-6. https:// doi.org/10.1016/j.prevetmed.2018.03.001.

33. Shen H, Wang C, Madson DM, Opriessnig T. High prevalence of porcine circovirus viremia in newborn piglets in five clinically normal swine breeding herds in North America. Prev Vet Med. 2010;97(3-4):228-36. https://doi.org/10.1016/j.prevetmed.2010.09.020.

34. Saha D, Del Pozo Sacristán R, Van Renne N, Huang L, Decaluwe R, Michiels A, et al. Anti porcine circovirus type 2 (PCV2) antibody placental barrier leakage from sow to fetus: impact on the diagnosis of intra-uterine PCV2 infection. Virol Sin. 2014;29(2):136-8. https://doi.org/10.1007/s12250014-3432-z.

35. Feng H, Segalés J, Fraile L, López-Soria S, Sibila M. Effect of high and low levels of maternally derived antibodies on porcine circovirus type 2 (PCV2) infection dynamics and production parameters in PCV2 vaccinated pigs under field conditions. Vaccine. 2016;34(27):3044-50. https://doi.org/10.101 6/j.vaccine.2016.04.088.

36. Fraile L, Grau-Roma L, Sarasola P, Sinovas N, Nofrarías M, López-Jimenez R, et al. Inactivated PCV2 one shot vaccine applied in 3-week-old piglets: improvement of production parameters and interaction with maternally derived immunity. Vaccine. 2012;30(11):1986-92. https://doi.org/10.1016/j.va ccine.2012.01.008

37. Fort M, Sibila M, Pérez-Martín E, Nofrarías M, Mateu E, Segalés J. One dose of a porcine circovirus 2 (PCV2) sub-unit vaccine administered to 3-weekold conventional piglets elicits cell-mediated immunity and significantly reduces PCV2 viremia in an experimental model. Vaccine. 2009;27(30):40317. https://doi.org/10.1016/j.vaccine.2009.04.028. 
38. Haake M, Palzer A, Rist B, Weissenbacher-Lang C, Fachinger V, Eggen A, et al. Influence of age on the effectiveness of PCV2 vaccination in piglets with high levels of maternally derived antibodies. Vet Microbiol. 2014;168(24):272-80. https://doi.org/10.1016/j.vetmic.2013.11.012.

39. Figueras-Gourgues S, Fraile L, Segalés J, Hernández-Caravaca I, López-Úbeda R, García-Vázquez FA, et al. Effect of porcine circovirus 2 (PCV-2) maternally derived antibodies on performance and PCV-2 viremia in vaccinated piglets under field conditions. Porcine Health Manag. 2019;5(1):21. https://doi.org/1 0.1186/s40813-019-0128-7.

40. Kekarainen T, Segalés J. Porcine circovirus 2 immunology and viral evolution. Porcine Health Manag. 2015;1 (1):17. https://doi.org/10.1186/s4 0813-015-0012-z.

41. Xiao CT, Halbur PG, Opriessnig T. Global molecular genetic analysis of porcine circovirus type 2 (PCV2) sequences confirm the presence of four main PCV2 genotypes and reveals a rapid increase of PCV2d. J Gen Virol. 2015;96(Pt 7):1830-41. https://doi.org/10.1099/vir.0.000100.

42. Saporiti V, Huerta E, Correa-Fiz F, Grosse Liesner B, Duran O, Segalés J, et al. Detection and genotyping of porcine circovirus 2 (PCV-2) and detection of Porcine circovirus 3 (PCV-3) in sera from fattening pigs of different European countries. Transbound Emerg Dis. 2020;67(6):2521-31.

43. Correa-Fiz F, Franzo G, Llorens A, Segalés J, Kekarainen T. Porcine circovirus 2 (PCV-2) genetic variability under natural infection scenario reveals a complex network of viral quasispecies. Sci Rep. 2018;8(1):15469. https://doi. org/10.1038/s41598-018-33849-2.

44. Hesse R, Kerrigan M, Rowland RR. Evidence for recombination between PCV2a and PCV2b in the field. Virus Res. 2008;132(1-2):201-7. https://doi. org/10.1016/j.virusres.2007.10.013.

45. Pejsak Z, Podgórska K, Truszczyński M, Karbowiak P, Stadejek T. Efficacy of different protocols of vaccination against porcine circovirus type 2 (PCV2) in a farm affected by postweaning multisystemic wasting syndrome (PMWS). Comp Immunol Microbiol Infect Dis. 2010;33(6):e1-5. https://doi.org/10.101 6/j.cimid.2009.09.006.

46. Alarcon P, Rushton J, Wieland B. Cost of post-weaning multi-systemic wasting syndrome and porcine circovirus type-2 subclinical infection in England - an economic disease model. Prev Vet Med. 2013;110(2):88-102. https://doi.org/10.1016/j.prevetmed.2013.02.010.

47. Croghan C, Egeghy PP, editors. Methods of dealing with values below the limit of detection using SAS. Southern SAS User Group. St. Petersburg: USEPA; 2003.

48. Oliver-Ferrando S, Segalés J, López-Soria S, Callén A, Merdy O, Joisel F, et al. Evaluation of natural porcine circovirus type 2 (PCV2) subclinical infection and seroconversion dynamics in piglets vaccinated at different ages. Vet Res. 2016;47(1):121. https://doi.org/10.1186/s13567-016-0405-2.

49. Kumar S, Stecher G, Li M, Knyaz C, Tamura K. MEGA X: molecular evolutionary genetics analysis across computing platforms. Mol Biol Evol. 2018;35(6):1547-9. https://doi.org/10.1093/molbev/msy096.

\section{Publisher's Note}

Springer Nature remains neutral with regard to jurisdictional claims in published maps and institutional affiliations.

Ready to submit your research? Choose BMC and benefit from:

- fast, convenient online submission

- thorough peer review by experienced researchers in your field

- rapid publication on acceptance

- support for research data, including large and complex data types

- gold Open Access which fosters wider collaboration and increased citations

- maximum visibility for your research: over $100 \mathrm{M}$ website views per year

At BMC, research is always in progress.

Learn more biomedcentral.com/submissions 